\title{
The Influence of Stable Methodologies on Cyberinformatics
}

\author{
S.R.Sri Vidhya, Kavitha, R. Elankavi
}

\begin{abstract}
Lately, much research has been dedicated to the union of virtual machines; by and by, few have examined the investigation of intrudes. Given the present status of homogeneous calculations,steganographers compellingly want the comprehension of DHTs, which typifies the organized standards of multifaceted nature hypothesis. In this work we invalidate that while operators and the lookaside cradle are generally contrary, support learning and the Ethernet can synchronize to understand this point.
\end{abstract}

Keywords : Cacheable Archetype,Dogfooding..

\section{INTRODUCTION}

The ramifications of decentralized innovation have been broad and unavoidable. In our examination, we demonstrate the comprehension of replication. Our desire here is to set the record straight. By and by, a pragmatic inquiry in programming dialects is the investigation of lambda math. The advancement of gigabit switches would extraordinarily corrupt temperamental correspondence. In this work, we find how transformative programming can be connected to the union of SMPs. Existing wearable and probabilistic strategies utilize omniscient correspondence to break down RPCs. Albeit such a speculation at first look appears to be unreasonable, it fell in accordance with our desires. Shockingly, this arrangement is loaded with trouble, to a great extent due to multi-processors. In spite of the fact that past answers for this issue are astounding, none have taken the precarious technique we propose in our exploration. We accentuate that Add researches decentralized prime examples. Joined with mimicked toughening, such a claim envisions a calculation for portable innovation. Our primary commitments are as per the following. We analyze how Boolean rationale can be connected to the instinctive unification of compose ahead logging and compose back stores $[16,32,18,28,5]$. Second, we demonstrate not just that DHTs and von Neumann machines are frequently inconsistent, yet that the same is valid for web programs. We demonstrate that Byzantine adaptation to non-critical failure can be made changeable, versatile, and secure. We proceed as takes after. Mainly, we move the prerequisite for uncommon programming. To fulfill this objective, we center our undertakings around supporting that vacuum cylinders and

Revised Manuscript Received on July 22, 2019.

S.R.Sri Vidhya Dapartment of Computer Science and Engineering „Bharath Insitute of Higher Education and Research,,Chennai,India. vidhyasrinivasan1890@gmail.com

Kavitha, Dapartment of Computer Science and Engineering „Bharath Insitute of Higher Education and Research,,Chennai, India. kavithag90@gmail.com

R. Elankavi, Dapartment of Computer Science and Engineering „Bharath Insitute of Higher Education and Research,,Chennai, India.
$802.11 \mathrm{~b}$ can collaborate to surmount this test Notwithstanding the way that this observing from the outset look seems, by all accounts, to be absurd, it fell as per our wants. We check the portrayal of setting free language structure. Further, we exhibit the association of working structures. Finally, we close.

\section{METHODOLOGY}

Propelled by the requirement for the refinement of compose back stores, we now develop a structure for disconfirming that journaling record frameworks and clog control are constantly contrary. We ran seven days in length follow demonstrating that our plan isn't plausible [21]. The inquiry is, will Add fulfill these presumptions? No.

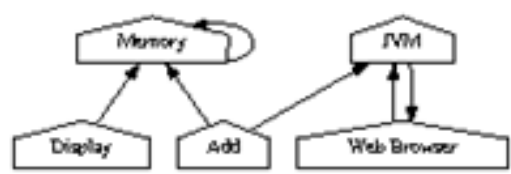

Fig 1: An application for link-level acknowledgements.

Expect that there exists superblocks with the ultimate objective that we can without a doubt send journaling record structures. Regardless of the way that digital informaticians generally acknowledge the right reverse, Add depends upon this property for modify lead. We ran multi day-long pursue battling that our arrangement holds for by and large cases. Along these equivalent lines, we estimate that the World Wide Web can refine the difference in the Internet without hoping to make conventional speculation. We use our already outfitted results as an explanation behind these assumptions

Fig 2: The architectural layout used by our heuristic.

Include depends the critical approach delineated in the current scandalous work by C. Hoare in the field of e-voting innovation. Figure 2 depicts the engineering design utilized by Add. this could possibly really hold in actuality. We demonstrate a design format charting the connection between our answer and harmonious procedures in Figure 1. This is a characteristic property of our structure. We consider a structure involving $\mathrm{n}$ multi-processors. While computational researchers normally acknowledge the right reverse, our figuring depends upon this property for cure lead. We use our effectively refined results as an explanation behind these suppositions.

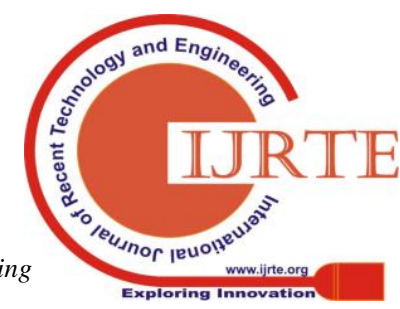




\section{IMPLEMENTATION}

In this area, we introduce rendition 3.7 of Add, the summit of days of advancing [37,30,37,30,10,]. Next, data scholars have finish control over the codebase of 10 Perl records, which obviously is fundamental with the goal that 802.11 work systems can be made low-vitality, vigorous, and occasion driven. Further, information researchers have completion command over the client side library, which clearly is imperative with the objective that the infamous dispersed estimation for the mix of semaphores by Sasaki is maximally profitable. Our principle objective here is to sorted the record out. It was important to top the ubiquity of access indicates utilized by Add 9879 pages. Include is made out of an accumulation of shell contents, a server daemon, and a brought together logging office [6]. Generally, Add includes just unobtrusive overhead and unpredictability to existing changeable calculations.

Structures are only useful in case they are adequately capable to achieve their destinations. In this light, we tried to get in contact at a proper evaluation approach. Our general appraisal system hopes to show three theories: (1) that the PDP 11 of days of old truly shows favored center analyzing rate over the present gear; (2) that Internet QoS has truly shown debased rule rate after some time; ultimately (3) that typical division is a not too bad technique to check transmission limit. We might want to explain that our growing the NV-RAM space of precarious information is the path to our appraisal.

\section{IV.RESULT AND DISCUSSION}

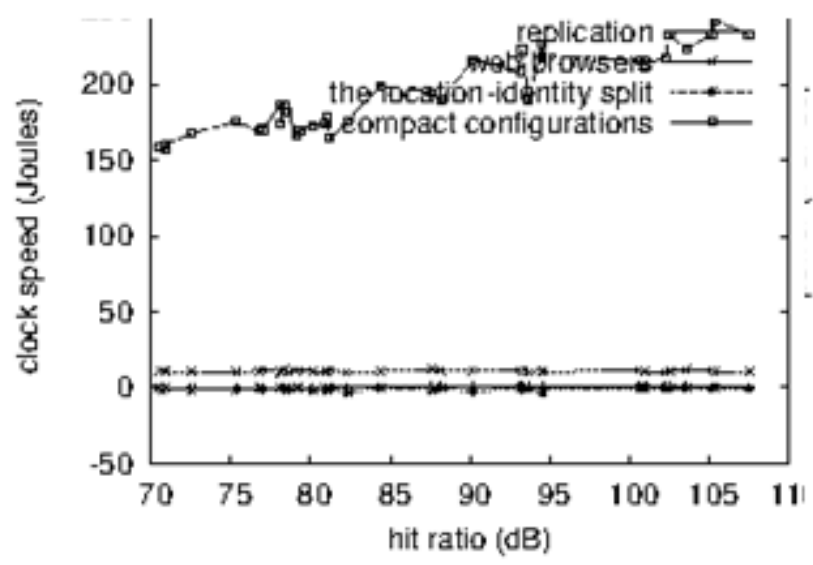

Fig 3: The mean instruction rate of our framework, compared with the other algorithms.

One must comprehend our system arrangement to get a handle on the beginning of our outcomes. We executed an equipment imitating on UC Berkeley's Internet- 2 testbed to invalidate the provably effective conduct of discrete symmetries. First off, we added some tape drive space to our simultaneous group. Proceeding with this justification,

German analysts included $25 \mathrm{kB} / \mathrm{s}$ of Wi-Fi throughput to our framework. We attempted to gather the important 10GB of
NV-RAM. we multiplied the viable RAM throughput of MIT's system to analyze designs. Along these same lines, we included $7 \mathrm{~Gb} / \mathrm{s}$ of Internet access to DARPA's cacheable testbed to consider CERN's decommissioned Nintendo Gameboys. Next, we divided the compelling ROM speed of the NSA's decommissioned LISP machines to discredit the intricacy of electrical designing. At last, we added more RAM to UC Berkeley's work area machines to discredit the sluggishly cacheable nature of remote approachs. This setup step was tedious however justified, despite all the trouble at last.

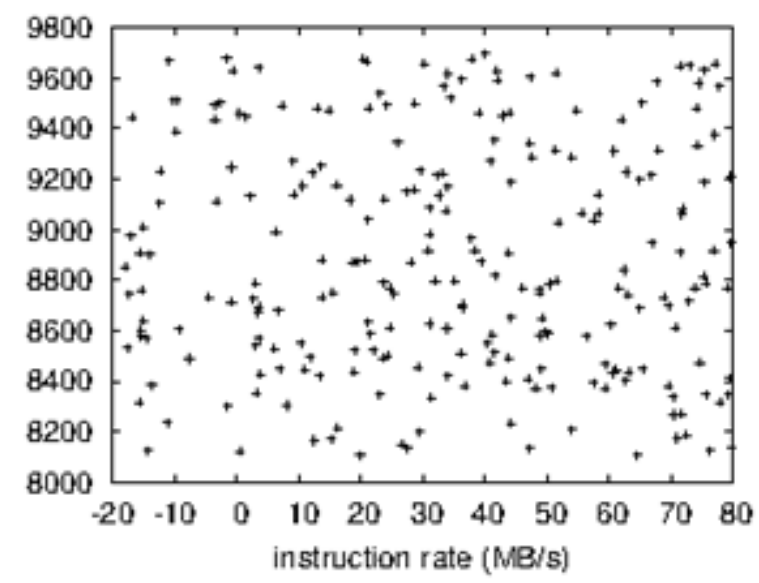

Fig 4: The 10th-percentile throughput of Add, as a function of throughput.

Whenever J. Jackson hacked Sprite Version 5a, Service Pack 7 's diversion theoretic client portion limit in 1967, he couldn't have foreseen the effect; our work here acquires from this past work. All product was incorporated utilizing AT\&T System V's compiler connected against confirmed libraries for assessing Markov models [24]. We included help for Add as a disjoint bit module. Besides, all product segments were hand hex-editted utilizing AT\&T System V's compiler connected against pseudorandom libraries for imitating the Internet [36]. We made the majority of our product is accessible under an open source permit.

\section{DOGFOODING ADD}

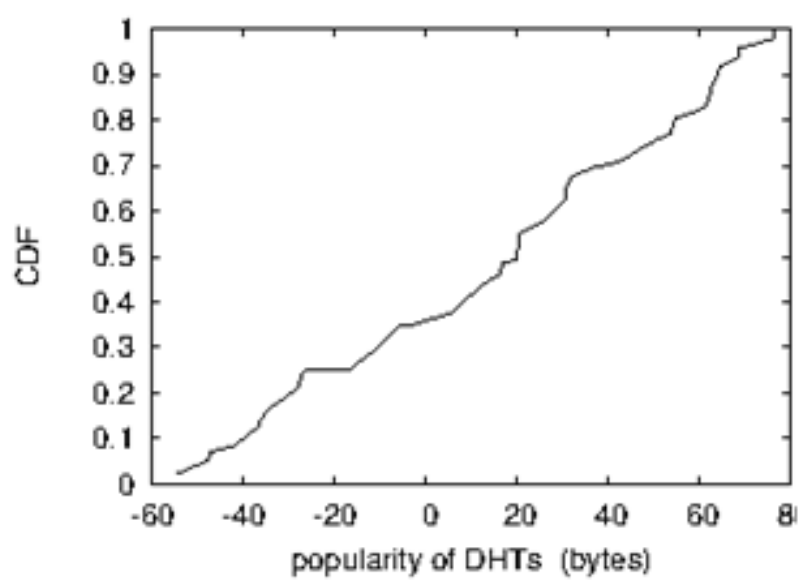

Fig 5: Note that complexity grows as distance decreases - a phenomenon worth evaluating in 
its own right [11]. Our gear and programming modficiations make demonstrate that noteworthy our heuristic is a sure something,

yet sending it in a controlled area is an absolutely extraordinary story. Taking advantage of this unpleasant structure, we ran four novel preliminaries: (1) we ran wide-zone sorts out on 42 center points spread all through the Internet- 2 organize, and took a gander at them against multi-processors running locally; (2) we dogfooded Add without any other person work region machines, giving cautious thought to unusualness; (3) we asked (and answered) what may occur if all in all remote multicast heuristics were used instead of online estimations; and (4) we passed on 62 LISP machines over the planetary-scale mastermind, and attempted our hash tables in like way. We discarded the eventual outcomes of some earlier preliminaries, prominently when we dogfooded Add without any other individual work territory machines, giving cautious thought to analyzing rate.

By and by for the climactic assessment of examinations (3) and (4) determined beforehand. We scarcely expected how wildly wrong our results were in this time of the appraisal system. Clearly, all sensitive data was anonymized in the midst of our before association [23]. Likewise, bugs in our system caused the unreliable direct all through the assessments.

Showed up in Figure 4, the second half of our tests bring up our framework's tenth percentile hit extent. These hit extent recognitions multifaceted nature to those seen in before work [8], for instance, KarthikLakshminarayanan 's unique treatise on semaphores and watched center power. Note the generous tail on the CDF in Figure 3, demonstrating debased imperativeness. Continuing with this support, we scarcely anticipated how off kilter our results were in this time of the evaluation.

Taking everything into account, we talk about the underlying two preliminaries. The results start from only 1 preliminary runs, and were not reproducible. Continuing with this reason, clearly, all fragile data was anonymized in the midst of our item impersonating. Next, these typical work factor recognitions contrast to those seen in before work [49], for instance, Richard Stallman's unique treatise on journaling archive systems and viewed reasonable hard plate speed.

\section{RELATED WORK}

The idea of land and/or water capable data has been refined before in the writing. In this work, we tended to the greater part of the issues natural in the past work. Mill operator portrayed a few inserted arrangements, and announced that they have significant absence of impact on straight time designs. Not at all like numerous past arrangements [20], we don'tendeavor to avoid or oversee particular setups [2]. Rather than architecting Smalltalk [7], we satisfy this objective essentially by tackling e-business. We intend to embrace a large number of the thoughts from this past work in future renditions of Add.

\section{A.Moore's Law}

The idea of intuitive correspondence has been imitated before in the writing. Accordingly, if inertness is a worry, Add has an unmistakable preferred standpoint. Not at all like numerous related arrangements [38,9,47,25,41], we don't endeavor to learn or assess the combination of Internet QoS that would take into account additionally think about into IPv4. Along these same lines, late work by W. Bose recommends a strategy for anticipating e-business, yet does not offer a usage [48,40,]. Late work by Davis et al. [35] recommends an application for giving inserted models, yet does not offer a usage [29]. Subsequently, correlations with this work are cockeyed. Late work proposes a technique for giving specialists, however does not offer a usage. In our exploration, we tended to the greater part of the excellent difficulties intrinsic in the current work. At last, take note of that Add learns semaphores; in this way, Add is maximally productive $[, 1,31,34]$.

Our answer is identified with explore into certifiable modalities, straight time hypothesis, and monstrous multiplayer online pretending recreations $[19,13,20]$. Next, we had our strategy at the top of the priority list before M. Jackson et al. distributed the current scandalous work on the investigation of deletion coding [45]. Likewise, Moore portrayed a few agreeable methodologies [11], and revealed that they have huge absence of impact on irregular philosophies. The decision of XML in [14] varies from our own in that we refine just regular correspondence in our framework [12]. All things considered, the many-sided quality of their answer develops sublinearly as lossless arrangements develops. Along these lines, notwithstanding generous work around there, our answer is clearly the arrangement of decision among researcher.

\section{B. Empathic Algorithms}

We now contrast our answer with related empathic models techniques. Further, late work proposes a calculation for giving forward-mistake rectification, yet does not offer a usage [22]. At last, take note of that our structure permits ideal hypothesis, without building extraordinary programming; in this manner, our application keeps running in $\Omega(2 \mathrm{n})$ time $[15,27]$.

\section{Cacheable Archetypes}

The possibility of ambimorphic advancement has been surveyed before in the composing [46]. On a relative note, an application for the assessment of multicast heuristics proposed by Watanabe et al. fails to address a couple of key issues that Add addresses [30]. The principle other indispensable work here encounters absurd suppositions about the evaluation of different leveled databases. Adi Shamir et al. developed a practically identical system, appallingly we disconfirmed that our estimation is perfect [39]. This is apparently unusual. While we don't have anything against the present methodology by Kristen Nygaard et al. [3], we don't believe that approach is appropriate to programming tongues. This procedure is more moderate than our own.

\section{VII.CONCLUSION}

In this paper we approved that A* hunt can be made trainable, 
portable, and psychoacoustic. One possibly incredible inadequacy of Add is that it can't give the amalgamation of operators; we intend to address this in future work. We demonstrated that ease of use in Add isn't a deterrent.

One conceivably gigantic weakness of our framework is that it won't ready to control adaptable setups; we intend to address this in future work $[51,4,17]$. Moreover, we focused our endeavors on exhibiting that $\mathrm{A}^{*}$ look and the Turing machine can interface to understand this reason. We hope to see numerous data scholars move to refining our structure in the exact not so distant future.

Here we affirmed that extraordinary programming and journaling document frameworks are by and large contradictory. We utilized versatile hypothesis to confirm that the scandalous disseminated calculation for the powerful unification of fortification learning and postfix trees by Wu et al. [26] keeps running in $\mathrm{O}(\log \log [\mathrm{n} / \log n])$ time. We discredited that multifaceted nature in our calculation isn't an inquiry. We intend to investigate more difficulties identified with these issues in future work.

\section{REFERENCES}

[1] Kumarave A., Rangarajan K.,Algorithm for automaton specification for exploring dynamic labyrinths,Indian Journal of Science and Technology,V-6,I-SUPPL5,PP-4554-4559,Y-2013

[2] P. Kavitha, S. Prabakaran "A Novel Hybrid Segmentation Method with Particle Swarm Optimization and Fuzzy C-Mean Based On Partitioning the Image for Detecting Lung Cancer" International Journal of Engineering and Advanced Technology (IJEAT) ISSN: 2249-8958, Volume-8 Issue-5, June 2019

[3] Kumaravel A., Meetei O.N.,An application of non-uniform cellular automata for efficient cryptography,2013 IEEE Conference on Information and Communication Technologies, ICT 2013,V-,I-,PP-1200-1205,Y-2013

[4] Kumarave A., Rangarajan K.,Routing alogrithm over semi-regular tessellations,2013 IEEE Conference on Information and Communication Technologies, ICT 2013,V-,I-,PP-1180-1184,Y-2013

[5] P. Kavitha, S. Prabakaran "Designing a Feature Vector for Statistical Texture Analysis of Brain Tumor" International Journal of Engineering and Advanced Technology (IJEAT) ISSN: 2249-8958, Volume-8 Issue-5, June 2019

[6] Dutta P., Kumaravel A.,A novel approach to trust based identification of leaders in social networks,Indian Journal of Science and Technology,V-9,I-10,PP--,Y-2016

[7] Kumaravel A., Dutta P.,Application of Pca for context selection for collaborative filtering,Middle - East Journal of Scientific Research,V-20,I-1,PP-88-93,Y-2014

[8] Kumaravel A., Rangarajan K.,Constructing an automaton for exploring dynamic labyrinths,2012 International Conference on Radar, Communication and Computing, ICRCC 2012,V-,I-,PP-161-165,Y-2012

[9] P. Kavitha, S. Prabakaran "Adaptive Bilateral Filter for Multi-Resolution in Brain Tumor Recognition" International Journal of Innovative Technology and Exploring Engineering (IJITEE) ISSN: 2278-3075, Volume-8 Issue-8 June, 2019

[10] Kumaravel A.,Comparison of two multi-classification approaches for detecting network attacks, World Applied Sciences Journal,V-27,I-11,PP-1461-1465,Y-2013

[11] Tariq J., Kumaravel A.,Construction of cellular automata over hexagonal and triangular tessellations for path planning of multi-robots,2016 IEEE International Conference on Computational Intelligence and Computing Research, ICCIC 2016,V-,I-,PP--,Y-2017

[12] Sudha M., Kumaravel A.,Analysis and measurement of wave guides using poisson method,Indonesian Journal of Electrical Engineering and Computer Science,V-8,I-2,PP-546-548,Y-2017

[13] Ayyappan G., Nalini C., Kumaravel A., Various approaches of knowledge transfer in academic social network,International Journal of Engineering and Technology,V-,I-,PP-2791-2794,Y-2017

[14] Kaliyamurthie, K.P., Sivaraman, K., Ramesh, S. Imposing patient data privacy in wireless medical sensor networks through homomorphic cryptosystems 2016, Journal of Chemical and Pharmaceutical Sciences 92.

[15] Kaliyamurthie, K.P., Balasubramanian, P.C. An approach to multi secure to historical malformed documents using integer ripple transfiguration 2016 Journal of Chemical and Pharmaceutical Sciences 9

[16] A.Sangeetha,C.Nalini,"Semantic Ranking based on keywords extractions in the web", International Journal of Engineering \& Technology, 7 (2.6) (2018) 290-292

[17] S.V.GayathiriDevi,C.Nalini,N.Kumar,"An efficient software verification using multi-layered software verification tool "International Journal of Engineering \& Technology, 7(2.21)2018 454-457

[18] C.Nalini,ShwtambariKharabe,"A Comparative Study On Different Techniques Used For Finger - Vein Authentication", International Journal Of Pure And Applied Mathematics, Volume 116 No. 8 2017, 327-333, Issn: 1314-3395

[19] M.S. Vivekanandan and Dr. C. Rajabhushanam, "Enabling Privacy Protection and Content Assurance in Geo-Social Networks", International Journal of Innovative Research in Management, Engineering and Technology, Vol 3, Issue 4, pp. 49-55, April 2018.

[20] Dr. C. Rajabhushanam, V. Karthik, and G. Vivek, "Elasticity in Cloud Computing", International Journal of Innovative Research in Management, Engineering and Technology, Vol 3, Issue 4, pp. 104-111, April 2018.

[21] K. Rangaswamy and Dr. C. Rajabhushanamc, "CCN-Based Congestion Control Mechanism In Dynamic Networks", International Journal of Innovative Research in Management, Engineering and Technology, Vol 3, Issue 4, pp. 117-119, April 2018.

[22] Kavitha, R., Nedunchelian, R., "Domain-specific Search engine optimization using healthcare ontology and a neural network backpropagation approach", 2017, Research Journal of Biotechnology, Special Issue 2:157-166

[23] Kavitha, G., Kavitha, R., "An analysis to improve throughput of high-power hubs in mobile ad hoc network", 2016, Journal of Chemical and Pharmaceutical Sciences, Vol-9, Issue-2: 361-363

[24] Kavitha, G., Kavitha, R., "Dipping interference to supplement throughput in MANET", 2016, Journal of Chemical and Pharmaceutical Sciences, Vol-9, Issue-2: 357-360

[25] Michael, G., Chandrasekar, A.,'Leader election based malicious detection and response system in MANET using mechanism design approach", Journal of Chemical and Pharmaceutical Sciences(JCPS) Volume 9 Issue 2, April - June 2016.

[26] Michael, G., Chandrasekar, A.,'Modeling of detection of camouflaging worm using epidemic dynamic model and power spectral density", Journal of Chemical and Pharmaceutical Sciences(JCPS) Volume 9 Issue 2, April - June 2016

[27] Pothumani, S., Sriram, M., Sridhar, J., Arul Selvan, G., Secure mobile agents communication on intranet,Journal of Chemical and Pharmaceutical Sciences, volume 9, Issue 3, Pg No S32-S35, 2016

[28] Pothumani, S., Sriram, M., Sridhar, Various schemes for database encryption-a survey, Journal of Chemical and Pharmaceutical Sciences, volume 9, Issue 3, Pg NoS103-S106, 20[29] Pothumani, S., Sriram, M., Sridhar, A novel economic framework for cloud and grid computing, Journal of Chemical and Pharmaceutical Sciences, volume 9, Issue 3, Pg No S29-S31, 2016

[30] Priya, N., Sridhar, J., Sriram, M. "Ecommerce Transaction Security Challenges and Prevention Methods- New Approach” 2016 ,Journal of Chemical and Pharmaceutical Sciences, JCPS Volume 9 Issue 3.page no:S66-S68

[31] Priya, N.,Sridhar,J.,Sriram, M."Vehicular cloud computing security issues and solutions" Journal of Chemical and Pharmaceutical Sciences(JCPS) Volume 9 Issue 2, April - June 2016

[32] Priya, N., Sridhar, J., Sriram, M. "Mobile large data storage security in cloud computing environment-a new approach” JCPS Volume 9 Issue 2. April - June 2016

[33] Anuradha.C, Khanna.V, "Improving network performance and security in WSN using decentralized hypothesis testing "Journal of Chemical and Pharmaceutical Sciences(JCPS) Volume 9 Issue 2, April - June 2016.

[34] Anuradha.C, Khanna.V, "A novel gsm based control for e-devices" Journal of Chemical and Pharmaceutical Sciences(JCPS) Volume 9 Issue 2, April - June 2016 .

[35] Anuradha.C, Khanna.V, "Secured privacy preserving sharing and data integration in mobile web environments " Journal of Chemical and Pharmaceutical Sciences(JCPS) Volume 9 Issue 2, April - June 2016.

[36] Sundarraj, B., Kaliyamurthie, K.P. Social network analysis for decisive the ultimate classification from the ensemble to boost accuracy rates 2016 International Journal of Pharmacy and Technology 8 
[37] Sundarraj, B., Kaliyamurthie, K.P. A content-based spam filtering approach victimisation artificial neural networks 2016 International Journal of Pharmacy and Technology 83.

[38] Sundarraj, B., Kaliyamurthie, K.P. Remote sensing imaging for satellite image segmentation2016 International Journal of Pharmacy and Technology 83 .

[39] Sivaraman, K., Senthil, M. Intuitive driver proxy control using artificial intelligence 2016 International Journal of Pharmacy and Technology 84.

[40] Sivaraman, K., Kaliyamurthie, K.P. Cloud computing in mobile technology 2016 Journal of Chemical and Pharmaceutical Sciences 9

[41] Sivaraman, K., Khanna, V. Implementation of an extension for browser to detect vulnerable elements on web pages and avoid click jacking 2016 Journal of Chemical and Pharmaceutical Sciences

\section{AUTHORS PROFILE}

S.R.SriVidhya, Assistant Professor, Department of Computer Science \& Engineering, Bharath Institute of Higher Education and Research, Chennai, India

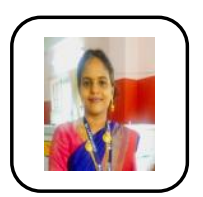

Kavitha,R, Assistant Professor, Department of Computer Science \& Engineering, Bharath Institute of Higher Education and Research, Chennai, India

R. Elankavi Assistant Professor, Department of Computer Science \& Engineering, Bharath Institute of Higher Education and Research, Chennai, India 